Proceedings

\title{
Association between Intake of Fermented Dairy Product and Diet Quality, Health Beliefs in a Representative Sample of Polish Population +
}

\author{
Katarzyna E. Przybyłowicz 1,* , Jakub Morze 1,2, Anna Danielewicz ${ }^{1}$, Katarzyna Staniewska ${ }^{3}$, \\ Aneta Dąbrowska ${ }^{4}$, Maria Baranowska ${ }^{4}$, Małgorzata Darewicz ${ }^{5}$, Justyna Żulewska ${ }^{4}$ and \\ Bogusław Staniewski ${ }^{4}$ \\ 1 Department of Human Nutrition, University of Warmia and Mazury in Olsztyn, 10-900 Olsztyn, Poland; \\ jakub.morze@uwm.edu.pl (J.M.); anna.danielewicz@uwm.edu.pl (A.D.) \\ 2 Department of Cardiology and Internal Diseases, University of Warmia and Mazury in Olsztyn, 10-900 \\ Olsztyn, Poland \\ 3 Department of Commodity Science and Food Analysis, University of Warmia and Mazury in Olsztyn, 10- \\ 900 Olsztyn, Poland; kasta@uwm.edu.pl \\ 4 Department of Dairy Science and Quality Management, University of Warmia and Mazury in Olsztyn, 10- \\ 900 Olsztyn, Poland; anetazj@uwm.edu.pl (A.D.); mbb@uwm.edu.pl (M.B.); justyna.żulweska@uwm.edu.pl \\ (J.Ż); bost@uwm.edu.pl (B.S.) \\ 5 Chair of Food Biochemistry, University of Warmia and Mazury in Olsztyn, 10-900 Olsztyn, Poland; \\ darewicz@uwm.edu.pl \\ * Correspondence: katarzyna.przybylowicz@uwm.edu.pl; Tel.: +48-89-524-5521 \\ + Presented at the The 1st International Electronic Conference on Nutrients - Nutritional and Microbiota \\ Effects on Chronic Disease, 2-15 November 2020. Available online: https://iecn2020.sciforum.net/.
}

Published: 30 October 2020

\begin{abstract}
This study aimed to evaluate the association between diet quality, perception of benefits consumption, and dairy fermented product intake in a representative sample of the Polish population. The study was carried out in February 2020 in 2009, men and women randomly sampled from the representative Polish population stratified for two age groups (19-30 and 66-75 years). Dairy product intake was evaluated using a qualitative frequency questionnaire. Diet quality was assessed by calculating the Mediterranean Diet Adherence Screener (MEDAS) score. Perceived health benefits of dairy products consumption were assessed with a literature-based questionnaire. The Health Concern Scale was used to measure participants' attitudes toward health. Median intake of fermented dairy products was 0.8 portion/day (IQR: 0.4-1.6). Intake of fermented dairy products was associated with higher MEDAS. We observed that people with the highest intake of dairy fermented products consumed more oils, vegetables, wine, legumes, fish and seafood, sweets and pastries, nuts, and higher preference for white meat and were more likely to report perceived benefits to maintain body weight, reduce cardiovascular risk, and improve immune and dental health. Moreover, a high intake of fermented dairy products was positively related to paying more attention to health. Our study identified patterns of health behaviours associated with frequent consumption of fermented products. We observed that the intake of fermented dairy products is associated with better diet quality, consumer self-consciousness, and a greater attitude to own health.
\end{abstract}

Keywords: dairy; fermented dairy; Mediterranean Diet; diet quality; health benefits; health beliefs; health concern 


\section{Introduction}

Dairy products are an excellent source of valuable nutrients such as protein, calcium and vitamins, and are therefore considered to be one of the main elements of a balanced diet. Also, some studies suggest that supplementation with dairy foods healthy dietary patterns like the Mediterranean diet may improve health outcomes [1]. Adequate consumption of dairy products has the potential to protect against non-communicable chronic diseases such as type 2 diabetes, cardiovascular diseases and certain cancers. However, it is fermented dairy products that are particularly important because of their beneficial health effects. The presence of peptides released during proteolysis, the higher bioavailability of certain vitamins and minerals and bacterial and yeast cultures are associated with additional benefits for the body. This effect may consist in the modulation of immune function, intestinal microbiota, exclusion of pathogens, decrease allergy and may benefit in many other causes of health deterioration [2].

The intention to maintain health may be one of the reasons for choosing particular groups of foods. The high share of fermented milk products in the diet of Polish consumers results from their belief in the benefits of their consumption [3]. However, these beliefs do not always concern the perception of all possible beneficial health effects.

Thus, this study aimed to evaluate the association between diet quality, perception of benefits consumption, and dairy fermented product intake in a representative sample of the Polish population.

\section{Materials and Methods}

\subsection{Sample Collection}

The attempt to survey Poles' opinions on dairy products and their aspect of innovation was representative, nationwide and included 2009 Poles aged 19-30 and 66-75. The survey was conducted using computer assisted personal interviews (CAPI) in January and February 2020. The sample for the survey had a quota-random character. Due to the lack of data on food consumption, the sample studied comprised 1695 people.

\subsection{Questionnaires}

The structured questionnaire concerned the study of consumer behaviour on the market of innovative dairy products with pro-healthy properties and the study of expectations towards these products. The questionnaire covered 8 thematic groups and contained a total of 83 questions giving 302 result variables.

Dairy products consumption was assessed using a qualitative food frequency questionnaire where questions were created on the basis of the validated KomPAN questionnaire [4] and Codex Alimentarius dairy food grouping. Total fermented dairy product consumption was calculated as a sum of natural and sweetened fermented dairy products and rennet cheeses.

Diet quality was described with the German version of the Mediterranean Diet Adherence Screener (MEDAS) score [5]. The questionnaire consists of 14 questions concerning the consumption of selected food groups. However, an original question relating to a dish with a traditional sauce of tomatoes, garlic, onion, or leeks sautéed in olive oil, was changed to servings of whole-grain cereal products. The questionnaire result allows assessing to what extent the diet of the examined person is consistent with the pattern of the Mediterranean diet. This allowed for the selection of groups whose diet was consistent with the principles of proper nutrition or was different from them.

The Health Concern Scale (HCS) [6] allowed for the assessment of the respondents' attitude to health. The questionnaire consists of 10 statements concerning the interest in health and the relationship with excessive consumption of sugar, fat, salt, cholesterol and food additives with the occurrence of selected diseases.

The questions related to the health benefits of regular consumption of all analysed dairy product was created based on the literature. The questions concerned weight management, heart, bone, 
digestive and dental health and immune defence, however, respondents could also indicate no benefits.

\subsection{Confounding factors}

Participants declared a measure of weight, height and waist circumference. On this basis body mass index (BMI) was calculated $\left(\mathrm{kg} / \mathrm{m}^{2}\right)$ and classified as underweight $\left(<18.50 \mathrm{~kg} / \mathrm{m}^{2}\right)$ normal $(18.50$ $\left.24.99 \mathrm{~kg} / \mathrm{m}^{2}\right)$ and overweight and obesity $\left(\geq 25.00 \mathrm{~kg} / \mathrm{m}^{2}\right)$. Other confounders which were taken into account were: age cohort (19-30 y, 66-75 y), gender (women, men), smoking status (current, former, never), sleeping time ( $<6 \mathrm{~h}, 6-9 \mathrm{~h},>9 \mathrm{~h}$ ), TV watching time ( $<2 \mathrm{~h}, 2-4 \mathrm{~h}, 4-6 \mathrm{~h}, 6-8 \mathrm{~h}, 8-10 \mathrm{~h},>10 \mathrm{~h}$ ), education level (primary, secondary, vocational, higher, not wish to answer), economic status (very poor, poor, medium, good, very good, not wish to answer).

\subsection{Statistical analysis}

Variables were presented as the median and interquartile range (IQR) if were continuous and as percentage and number if were categorical. Differences of continuous variables across quartiles of total fermented dairy product consumption were evaluated using Kruskal-Wallis test and Dunn's post-hoc test. Differences of categorical variables were obtained using chi-square or Fisher's exact test.

The associations between quintiles of total fermented dairy products consumption and MEDAS, its component, HCS and health benefits were evaluated by the generalized linear model. In all analysis adjustment set (age cohort, gender, smoking status, sleeping time, TV watching time, education level, economic status (all categorical)) was used. Results were presented as backtransformed least square means and their $95 \%$ confidence interval $(95 \% \mathrm{CI})$.

The significance level was set to $p<0.05$. The statistical analysis was carried out using STATISTICA software (version 13.1 PL; StatSoft Inc.: Tulsa, USA/ Inc: Kraków, Poland).

\section{Results}

Table 1 shows the basic characteristics of the studied sample by quintiles of total fermented dairy products that the median intake was $0.8(0.4 ; 1.6)$. Participants in Q5 compared with Q3 were younger (25 years vs. 27 years, respectively) and declared higher waist circumference $(87 \mathrm{~cm}$ vs. $80 \mathrm{~cm}$, respectively). Participants who consumed more fermented dairy products were more likely to be women, watch TV more than $6 \mathrm{~h}$ per day and less likely sleep 6-9 $\mathrm{h}$.

Table 1. Basic characteristics.

\begin{tabular}{|c|c|c|c|c|c|c|}
\hline & \multicolumn{5}{|c|}{ Total Fermented Dairy Products Consumption } & \multirow[b]{2}{*}{$p$} \\
\hline & Q1 & Q2 & Q3 & Q4 & Q5 & \\
\hline $\begin{array}{l}\text { Fermented dairy product consumption, } \\
\text { times } / \mathrm{d}+\end{array}$ & $\begin{array}{c}0.2(0.1 \\
0.2)\end{array}$ & $\begin{array}{c}0.4(0.3 ; \\
0.7)\end{array}$ & $\begin{array}{c}0.8(0.7 \\
0.9)\end{array}$ & $\begin{array}{c}1.2(1.2 ; \\
1.3)\end{array}$ & $\begin{array}{l}2.1(1.7 \\
2.6)\end{array}$ & $<0.001$ \\
\hline Age cohort $19-30 \mathrm{y}$, years $\dagger$ & $26(23 ; 28)$ & $26(23 ; 29)$ & $\begin{array}{c}27(24 ; \\
29)^{a}\end{array}$ & $26(22 ; 28)$ & $\begin{array}{c}25(21 ; \\
28)^{\mathrm{a}}\end{array}$ & 0.022 \\
\hline Age cohort $66-75$ y, years $\uparrow$ & $69(67 ; 71)$ & $69(67 ; 71)$ & $68(67 ; 70)$ & $69(67 ; 71)$ & $69(67 ; 71)$ & 0.310 \\
\hline Gender (women) & $48.1(148)$ & $51.3(180)$ & $58.7(186)$ & $53.2(166)$ & $59.0(240)$ & 0.015 \\
\hline Waist circumference, $\mathrm{cm} \quad \dagger$ & $\begin{array}{c}86(75 \\
100)\end{array}$ & $83(70 ; 95)$ & $\begin{array}{c}80(70 ; \\
90)^{\mathrm{a}}\end{array}$ & $85(75 ; 96)$ & $\begin{array}{c}87(76 ; \\
98)^{\mathrm{a}}\end{array}$ & 0.016 \\
\hline Body mass index, $\mathrm{kg} / \mathrm{m}^{2}+$ & $\begin{array}{c}25.5 \\
(22.7 ; \\
28.7)\end{array}$ & $\begin{array}{c}25.2 \\
(22.0 ; \\
27.9)\end{array}$ & $\begin{array}{c}24.8 \\
(22.2 ; \\
27.2)\end{array}$ & $\begin{array}{c}25.5 \\
(23.0 ; \\
28.1)\end{array}$ & $\begin{array}{c}25.1 \\
(22.3 ; \\
28.0)\end{array}$ & 0.132 \\
\hline$\%$ Overweight obese & $53.7(123)$ & $51.5(138)$ & $48.4(119)$ & $53.3(119)$ & $50.9(172)$ & 0.773 \\
\hline Smoking status (current) & $20.1(62)$ & $24.8(87)$ & $24.3(77)$ & $23.7(74)$ & $27.3(111)$ & 0.290 \\
\hline Physical activity (MVPA) & $61.0(188)$ & $65.8(231)$ & $68.8(218)$ & $65.4(204)$ & $61.2(249)$ & 0.170 \\
\hline TV watching time (more than $6 \mathrm{~h}$ ) & $12.3(38)$ & $17.4(61)$ & $16.4(52)$ & $18.9(59)$ & $24.3(99)$ & 0.001 \\
\hline Sleeping time $(6-9 \mathrm{~h})$ & $79.2(244)$ & $83.2(292)$ & $77.9(247)$ & $76.0(237)$ & $74.0(301)$ & 0.034 \\
\hline
\end{tabular}


$\begin{array}{lllllll}\text { Economic status (high and very high) } \quad 25.0(77) & 28.8(101) & 25.9(82) & 24.4(76) & 28.0(114) & 0.643\end{array}$ Education level (higher)

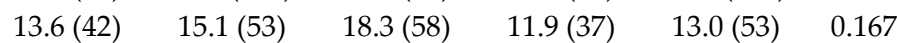

Data are presented as $\%$ and number or (where + ) median and interquartile range (IQR). The sample size may vary slightly in each variable due to missing data. MVPA, moderate-to-vigorous physical activity. $p$ value: significance for Kruskal-Wallis test (Dunn's post-hoc test) or Pearson's chi square test.

Table 2 presents the association between MEDAS score and its components and total dairy fermented products consumption. Intake of dairy fermented products was associated with higher MEDAS score. We observed that frequency of dairy fermented products consumption was positively associated with frequent consumption of oils, vegetables, wine, legumes, fish and seafood, sweets and pastries, nuts (for all $\left.P_{\text {trend }}<0.001\right)$ and a higher preference for white meat $\left(P_{\text {trend }}=0.014\right)$.

Table 2. Association between MEDAS, its components and total fermented dairy products consumption.

\begin{tabular}{ccccccc}
\hline & \multicolumn{7}{c}{ Total Fermented Dairy Products Consumption } & \multirow{2}{*}{ P $_{\text {trend }}$} \\
\cline { 2 - 6 } & $\mathbf{Q 1}$ & $\mathbf{Q} 2$ & $\mathbf{Q} 3$ & $\mathbf{Q 4}$ & $\mathbf{Q 5}$ & \\
\hline MEDAS score & $5.6(5.3 ; 5.9)$ & $5.8(5.4 ; 6.1)$ & $5.7(5.4 ; 6.1)$ & $6.0(5.6 ; 6.3)$ & $6.2(5.9 ; 6.6)$ & $<0.001$ \\
Plant oils as main (yes) + & $73.1(225)$ & $83.5(293)$ & $86.4(274)$ & $87.2(272)$ & $83.1(338)$ & 0.096 \\
Plant oils, times/d & $1.7(1.4 ; 2.0)$ & $1.7(1.5 ; 2.0)$ & $2.1(1.8 ; 2.4)$ & $2.0(1.7 ; 2.3)$ & $2.3(2 ; 2.6)$ & $<0.001$ \\
Vegetables, times/d & $2.7(2.3 ; 3.0)$ & $2.6(2.3 ; 3.0)$ & $2.5(2.2 ; 2.8)$ & $2.6(2.3 ; 3.0)$ & $3.1(2.8 ; 3.5)$ & $<0.001$ \\
Fruits and juices, times/d & $4.7(4.2 ; 5.3)$ & $5.2(4.6 ; 5.8)$ & $5.7(5.1 ; 6.3)$ & $5.5(4.9 ; 6.1)$ & $5.1(4.6 ; 5.7)$ & 0.451 \\
Red meat, times/d & $4.8(4.3 ; 5.5)$ & $5.1(4.5 ; 5.9)$ & $5.2(4.6 ; 5.9)$ & $6.0(5.3 ; 6.8)$ & $5.6(5.0 ; 6.3)$ & 0.168 \\
Butter and cream, times/d & $2.6(2.2 ; 2.9)$ & $2.5(2.2 ; 2.9)$ & $3.1(2.7 ; 3.5)$ & $2.6(2.3 ; 3.0)$ & $2.9(2.6 ; 3.3)$ & 0.084 \\
Sweetened beverages, times/d & $4.0(3.3 ; 4.8)$ & $5.0(4.1 ; 6.0)$ & $4.9(4.1 ; 5.8)$ & $4.6(3.8 ; 5.6)$ & $4.5(3.8 ; 5.4)$ & 0.687 \\
Wine, times/wk & $1.4(1.1 ; 1.8)$ & $1.6(1.2 ; 2.1)$ & $1.4(1.1 ; 1.9)$ & $1.9(1.4 ; 2.4)$ & $2.5(2.1 ; 3.1)$ & $<0.001$ \\
Legumes, times/wk & $1.2(1.0 ; 1.5)$ & $1.4(1.2 ; 1.7)$ & $1.7(1.5 ; 2.1)$ & $1.7(1.4 ; 2.0)$ & $2.0(1.7 ; 2.4)$ & $<0.001$ \\
Fish and seafood, times/wk & $1.3(1.1 ; 1.6)$ & $1.6(1.4 ; 1.9)$ & $1.7(1.4 ; 2.0)$ & $1.9(1.6 ; 2.2)$ & $2.1(1.9 ; 2.4)$ & $<0.001$ \\
Sweets and pastries, times/wk & $3.7(3.2 ; 4.2)$ & $4.0(3.5 ; 4.6)$ & $4.5(4.0 ; 5.1)$ & $4.4(3.8 ; 5.0)$ & $4.9(4.4 ; 5.5)$ & $<0.001$ \\
Nuts, times/wk & $0.6(0.4 ; 0.9)$ & $0.8(0.5 ; 1)$ & $1.1(0.8 ; 1.4)$ & $1.1(0.8 ; 1.5)$ & $1.6(1.3 ; 2.1)$ & $<0.001$ \\
Preferable white meat (yes) + & $71.4(220)$ & $75.2(264)$ & $73.2(232)$ & $79.8(249)$ & $80.6(328)$ & 0.014 \\
Whole grain products, times/d & $2.5(2.1 ; 2.9)$ & $2.5(2.1 ; 2.9)$ & $2.6(2.3 ; 3.1)$ & $2.7(2.4 ; 3.2)$ & $2.6(2.3 ; 3.0)$ & 0.179 \\
\hline
\end{tabular}

Data are presented as back-transformed least square means and $95 \%$ confidence interval (CI) or (where $\dagger$ ) as \% and number. The sample size may vary slightly in each variable due to missing data. MEDAS, MEDAS, Mediterranean Diet Adherence Screener. All data adjusted for age cohort, gender, smoking status, sleeping time, TV watching time, education level, economic status (all categorical). $p$ value: significance for Wald's test.

The results of the association between HSC, perceiving health benefits and total dairy fermented products consumptions are shown in Table 3 . High intake of dairy fermented products was positively related to paying more attention to health. Participants were more likely to report perceived health benefits to maintain normal body weight $(\mathrm{Q} 5=39.6 \% \mathrm{vs}$. $\mathrm{Q} 1=26.3 \%)$, reduce cardiovascular risk (Q5 $=52.3 \%$ vs. $\mathrm{Q} 1=26.6 \%)$, and improve immune $(\mathrm{Q} 5=67.3 \%$ vs. $\mathrm{Q} 1=50.3 \%)$ and dental health $(\mathrm{Q} 5=$ $36.9 \%$ vs. Q1 $=27.3 \%$ ) together with higher consumption of dairy fermented products. Participants who did not indicate benefits for health was negatively associated with fermented dairy product consumption $(\mathrm{Q} 5=20.5 \%$ vs. $\mathrm{Q} 1=51.6 \%)$

Table 3. Association between health concern scale, health beliefs and total fermented dairy products consumption.

\begin{tabular}{ccccccc}
\hline & \multicolumn{5}{c}{ Total Fermented Dairy Products Consumption } & \multirow{2}{*}{$P_{\text {trend }}$} \\
\cline { 2 - 5 } & Q1 & Q2 & Q3 & Q4 & Q5 & \\
\hline \% (n) & $18.2(308)$ & $20.7(351)$ & $18.7(317)$ & $18.4(312)$ & $24.0(407)$ & \\
HCS score + & 37.1 & 36.6 & 36.2 & 37.3 & 39.5 & 0.002 \\
& $(35.3 ; 39.0)$ & $(34.8 ; 38.5)$ & $(34.4 ; 38.0)$ & $(35.5 ; 39.2)$ & $(37.7 ; 41.4)$ & \\
Normal body weight & $26.3(81)$ & $29.3(103)$ & $38.2(121)$ & $38.8(121)$ & $39.6(161)$ & 0.001 \\
Healthy heart & $26.6(82)$ & $32.5(114)$ & $39.4(125)$ & $46.2(144)$ & $52.3(213)$ & $<0.001$ \\
Healthy bones & $56.5(174)$ & $64.7(227)$ & $71.9(228)$ & $71.2(222)$ & $67.6(275)$ & 0.075 \\
\hline
\end{tabular}




\begin{tabular}{ccccccc}
\hline Improved immunity & $50.3(155)$ & $61.3(215)$ & $67.2(213)$ & $68.6(214)$ & $67.3(274)$ & 0.002 \\
Healthy digestive track & $59.1(182)$ & $63.8(224)$ & $68.5(217)$ & $70.8(221)$ & $61.2(249)$ & 0.449 \\
Healthy teeth & $27.3(84)$ & $29.3(103)$ & $37.5(119)$ & $36.5(114)$ & $36.9(150)$ & $<0.001$ \\
Not bring benefits & $51.6(195)$ & $37.3(131)$ & $26.2(83)$ & $29.2(91)$ & $20.6(84)$ & $<0.001$ \\
\hline
\end{tabular}

Data are presented as back transformed least square means and $95 \%$ confidence interval (CI) or (where + ) median and interquartile range (IQR). HCS, health concern scale. All data adjusted for age cohort, gender, smoking status, sleeping time, TV watching time, education level, economic status (all categorical).

\section{Discussion}

This study investigated dietary, lifestyle and behavioural determinants of dairy fermented products intake in a representative sample of the Polish population. We observed that people with higher diet quality, as assessed by adherence to the Mediterranean diet, reported a higher intake of dairy fermented products. In particular, regular consumers of fermented dairy products had a higher intake of plant oils, vegetables, wine, legumes, fish and seafood, sweets and nuts, as well as more frequently selected white rather than red meat. With respect to health attitudes, regular consumers paid more attention to their health. Moreover, higher intake of fermented dairy products was more frequently motivated by perceived benefits for musculoskeletal, circulatory, digestive and immunological systems.

One of the major implications of our study is that fermented dairy products can complement other components of a healthy diet [1]. Fermented dairy products are a primary source of prebiotics and probiotics. Furthermore, those products provide a variety of compounds including proteins, peptides, oligosaccharides, vitamins and organic acids (including fatty acids) with distinct health effects [2]. Benefits of fermented dairy products intake can be explained by immunological, anticarcinogenic, immunomodulatory, antiallergic, antioxidative as well as lipid-, glucose-, and bloodpressure-lowering effects. Considering, a high intake of fermented products as a part of healthy, the sustainable dietary pattern shows the potential to expand its health effects. A number of experimental studies [1,7-9] support this point, showing that healthy diets supplemented with fermented dairy products might be superior over diets which exclude those products. In particular, the promotion of fermented dairy products intake as a way to improve overall diet quality should be considered on countries and societies where those products are manufactured locally and available at relatively low cost $[3,10]$.

The second major implication reflects the target group for the promotion of fermented dairy products intake. Our findings indicated that lower intake is driven by in young age and male sex. The burden of health risks and exposures in a group of young adults is a key determinant of their status in further life. In this context, males are exposed to greater health harms represented among others by higher rates of smoking, excessive alcohol consumption or lower diet quality. In view of our findings and health benefits based on published literature, both groups can be considered as targets for interventions aiming to increase intake of fermented dairy products. Although those issues require further studies designed to achieve improvements in certain health outcomes by tailored, specific dietary interventions.

In conclusion, our study identified patterns of health behaviours associated with frequent consumption of fermented products. We observed that the intake of fermented dairy products is associated with better diet quality, consumer self-consciousness, and a greater attitude to own health.

Author Contributions: Conceptualization, K.E.P. M.B., J.Ż., B.S.; methodology, K.E.P., A.D. (Anna Danielewicz), J.M., K.S., A.D. (Aneta Dąbrowska); formal analysis, A.D. (Anna Danielewicz) and J.M.; data curation, A.D. (Anna Danielewicz) and J.M.; writing-original draft preparation, K.E.P., A.D. (Anna Danielewicz) and J.M.; writing - review and editing, K.E.P., A.D. (Anna Danielewicz) and J.M.; visualization, A.D. (Anna Danielewicz) and J.M.; supervision, K.E.P., J.Ż. and B.S.; project administration, M.B., J.Ż., B.S. funding acquisition, J.Ż. and B.S. All authors have read and agreed to the published version of the manuscript.

Funding: This research and APC was funded by The National Centre for Research and Development, Project No. WPC1/DairyFunInn/2019, amount of funding 1.950.000.00 PLN. 
Conflicts of Interest: The authors declare no conflict of interest in the decision to publish the results.

\section{References}

1. Wade, A.T.; Davis, C.R.; Dyer, K.A.; Hodgson, J.M.; Woodman, R.J.; Murphy, K.J. A Mediterranean diet supplemented with dairy foods improves markers of cardiovascular risk: Results from the MedDairy randomized controlled trial. Am. j. Clin. Nutr. 2018, 108, 1166-1182, doi:10.1093/ajcn/nqy207.

2. García-Burgos, M.; Moreno-Fernández, J.; Alférez, M.J.M.; Díaz-Castro, J.; López-Aliaga, I. New perspectives in fermented dairy products and their health relevance. J. Funct. Foods 2020, 72, 104059, doi:10.1016/j.jff.2020.104059.

3. Sajdakowska, M.; Gębski, J.; Gutkowska, K.; Żakowska-Biemans, S. Importance of Health Aspects in Polish Consumer Choices of Dairy Products. Nutrients 2018, 10, 1007, doi:10.3390/nu10081007.

4. Jeżewska-Zychowicz, M.; Gawęcki, J.; Wądołowska, L.; Czarnocińska, J.; Galiński, G.; Kołłajtis-Dołowy, A.; Roszkowski, W.; Wawrzyniak, A.; Przybyłowicz, K.; Krusińska, B.; et al. Kwestionariusz do badania poglądów i zwyczajów żywieniowych dla osób w wieku od 16 do 65 lat, wersja 1.1-kwestionariusz administrowany przez ankietera-badacza. In Kwestionariusz do Badania Pogladów i Zwyczajów Żywieniowych Oraz Procedura Opracowania Danych; Gawęcki, J., Ed.; Human Nutrition Science Committee of the Polish Academy of Sciences: Warsaw, Poland, 2014; pp. 3-20.

5. Hebestreit, K.; Yahiaoui-Doktor, M.; Engel, C.; Vetter, W.; Siniatchkin, M.; Erickson, N.; Halle, M.; Kiechle, M.; Bischoff, S.C. Validation of the German version of the Mediterranean Diet Adherence Screener (MEDAS) questionnaire. BMC Cancer 2017, 17, 341, doi:10.1186/s12885-017-3337-y.

6. Kähkönen, P.; Tuorila, H. Consumer responses to reduced and regular fat content in different products: Effects of gender, involvement and health concern. Food Qual. Prefer. 1999, 10, 83-91, doi:10.1016/S09503293(98)00043-3.

7. de Moreno de Leblanc, A.; Perdigón, G. The application of probiotic fermented milks in cancer and intestinal inflammation. Proc. Nutr. Soc. 2010, 69, 421-428, doi:10.1017/s002966511000159x.

8. Pan, D.D.; Zeng, X.Q.; Yan, Y.T. Characterisation of Lactobacillus fermentum SM-7 isolated from koumiss, a potential probiotic bacterium with cholesterol-lowering effects. J. Sci. Food Agric. 2011, 91, 512-518, doi:10.1002/jsfa.4214.

9. Sharifi, M.; Moridnia, A.; Mortazavi, D.; Salehi, M.; Bagheri, M.; Sheikhi, A. Kefir: A powerful probiotics with anticancer properties. Med. Oncol. (Northwood Lond. Engl.) 2017, 34, 183, doi:10.1007/s12032-017-10449.

10. Górska-Warsewicz, H.; Rejman, K.; Laskowski, W.; Czeczotko, M. Milk and Dairy Products and Their Nutritional Contribution to the Average Polish Diet. Nutrients 2019, 11, 1771, doi:10.3390/nu11081771.

Publisher's Note: MDPI stays neutral with regard to jurisdictional claims in published maps and institutional affiliations.

(C) 2020 by the authors. Submitted for possible open access publication under the terms and conditions of the Creative Commons Attribution (CC BY) license (http://creativecommons.org/licenses/by/4.0/). 